\title{
Research on Regional Logistics Industry Development Strategy Based on System Dynamics: Take Changzhou as a Case
}

\author{
Zhi-Qing Zhang \\ College of Management, \\ Wuhan university of Science and Technology, \\ Research center of Hubei industry policy and management, \\ Wuhan, China \\ E-mail: zhangzhiqing@wust.edu.cn
}

\author{
Lang Yu, Wen-Hao Xie \\ College of Management, \\ Wuhan university of Science and Technology, \\ Wuhan, China \\ E-mail: 578072765@qq.com, 527486451@qq.com
}

\begin{abstract}
As an important part of regional economy, regional logistics is useful to improve the regional scale of production and processing, plays a crucial role in the areas of economic and social benefits, and promotes the competitiveness of enterprises and the regional economy. Based on the analysis of constituent elements of regional logistics system and the mutual relationship between the elements, we construct the regional logistics industry system dynamics model, and take Changzhou as an example to simulate the effect of regional logistics industry policy. It is helpful to put forward ways and means to promote the development of the Changzhou economy and logistics.
\end{abstract}

Keywords-Regional logistics industry; System dynamics; Strategy; Vensim PLE; Changzhou

\section{ESTABLISHMENT OF SYSTEM DYNAMICS MODEL OF REGIONAL LOGISTICS INDUSTRY'S DEVELOPMENT}

\section{A. Setting of System Boundary}

Regional logistics industry's development is directly affected by the level of regional economic development and the market demand, supplying capability, overstock and industry policies of logistics. These factors within the logistics system demonstrate a complicated causality. Therefore, a setting of system boundary of system dynamics model of regional logistics industry's development can be built: it mainly includes total value of regional GDP, capital of logistics industry, logistics backlog, investment in fixed assets of logistics and the whole society, the policy of logistics industry and education, and the actual demand and supply capacity of logistics.

\section{B. Assumptions of Model}

- To simplify the model, this model uses the regional GDP to measure the level of economic development, and considers only the impact of the amount of self-growth and impediment of regional economy;

- (2) The model only considers the impact of fixed asset investment in the regional economy;

- (3) The model considers only the influence of efficiency of logistics operations and logistics industry capital on regional logistics supply capacity, and that the efficiency of logistics operation is only related to the overall quality of the employees; the logistics industry capital is only related to the consumption (depreciation) and investment of logistics fixed capital.

- (4) The model only considers that regional logistics demand is associated with regional economic development.

\section{Construction of Model}

For further study of the interactive relationship between the development model of regional logistics industry and logistics backlog and industry capital, we construct a system dynamics model of regional logistics industry's development based on the analysis of causality of regional logistic industry's development, which is shown in Fig. 1. 


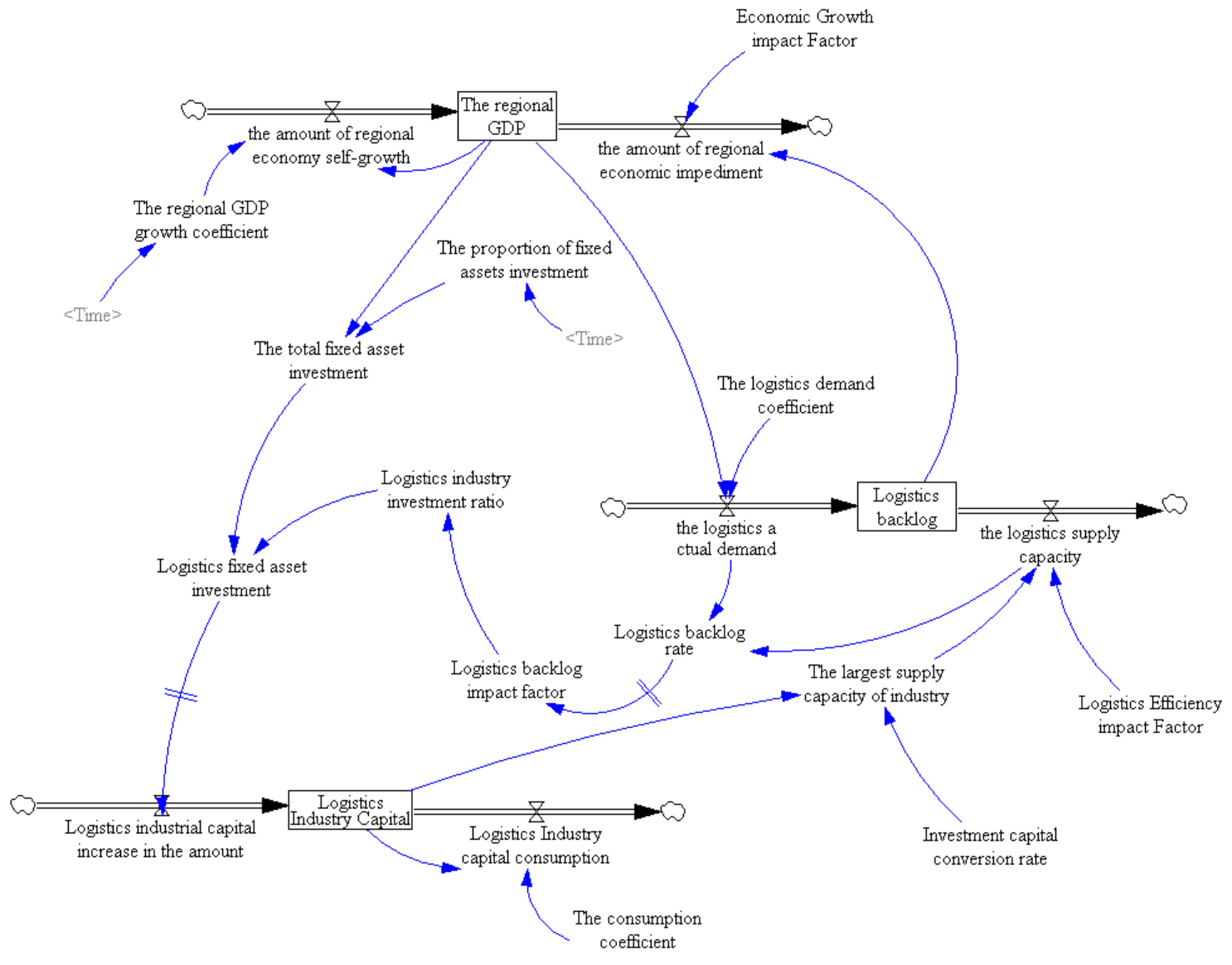

Figure 1. Regional industry development system dynamics model

The model consists of three interrelated sub-blocks (regional economic development, logistics backlog, logistics industrial capital), includes three level variables (the area's GDP, logistics backlog, logistics industrial capital), six rate variables (the amount of regional economic self-growth, the amount of regional economic impediment, the actual demand of logistics, logistics supply capacity, the increasing amount of logistics industry capital, the consumption of logistics industry), eight auxiliary variables (regional GDP growth coefficient, the proportion of investment in fixed assets, the proportion of investment in logistics industry, the proportion of investment in logistics fixed assets, the rate of logistics backlog, the overall proportion of investment in fixed assets, the largest industry supply capacity, the impact factor of logistics backlog ) and five constant (logistics demand coefficient, logistics consumption coefficient, the conversion rate of capital investment, impact factor of logistics efficiency, conversion rate of investment capital).

\section{Equation of System Model}

The equation of system dynamics model is constructed on the basis of model:
- $\quad$ The regional GDP = INTEG (the amount of regional economic self-growth - the amount of regional economic impediment, initial value);

- the amount of regional economy self-growth= The total regional GDP×the region's GDP growth factor;

- the amount of regional economic impediment= Logistics backlog $\times$ Economic Growth impact factor;

- $\quad$ The total fixed asset investment $=$ the region's GDP xproportion of investment in fixed assets;

- Economic Growth impact Factor $=\mathrm{C}$ (constant);

- Logistics backlog = INTEG (logistics actual demand logistics supply capacity, the initial value);

- $\quad$ the logistics actual demand $=$ region's GDP $\times$ logistics demand coefficient;

- the logistics supply capacity = industry's maximum supply capacity $\times$ logistics efficiency impact factor;

- Logistics backlog rate $=$ (the actual demand of logistics logistics supply capacity) / logistics actual demand;

- Logistics backlog impact factor = DELAY FIXED (logistics backlog rate, $\mathrm{C} 1, \mathrm{C} 2$ );

- $\quad$ Logistics Efficiency impact Factor $=\mathrm{C}($ constant $)$;

- Investment capital conversion rate $=\mathrm{C}$ (constant); 
- $\quad$ Logistics Industry Capital = INTEG (growth of logistics industry capital - capital consumption of the logistics industry, the initial value);

- Logistics industrial capital increase in the amount = DELAY FIXED (logistics and fixed asset investment, $\mathrm{C} 1, \mathrm{C} 2$ );

- Logistics Industry capital consumption = logistics industry capital consumption coefficient;

- Logistics fixed asset investment = total fixed asset investment $\times$ proportion of investment in logistics industry;

- $\quad$ The consumption coefficient $=\mathrm{C}$ (constant).

\section{SIMULATION AND EMULATION OF THE ISSUE}

Taking Changzhou City, Jiangsu Province as an example, we construct Changzhou City's system dynamics model of regional logistics industry's development, and use Vensim PLE (5.6a) to solve the model simulation based on the resulting data of Changzhou City's authoritative sites and Statistical Yearbook.

\section{A. Parameter Determination}

According to the Statistical Yearbook of Changzhou City and the parameter determination' $\mathrm{s}$ theory and method in Literature [9] and several empirical value, each variable's initial value of Changzhou City's system dynamics model of regional logistics industry's development is shown as Table 1.

TABLE I. INITIAL VALUE OF VARIABLES

\begin{tabular}{|c|c|}
\hline Name of variable & Initial value \\
\hline Regional GDP & 76.06 billion yuan \\
\hline Logistics backlog & 24.38 billion yuan \\
\hline Logistics industry capital & 7.86 billion yuan \\
\hline Consumption coefficient & 0.033 \\
\hline Economic Growth impact Factor & 0.015 \\
\hline Investment capital conversion rate & 20 \\
\hline Logistics efficiency impact factor & 0.35 \\
\hline Logistics demand coefficient & 3 \\
\hline Logistics backlog impact factor & DELAY FIXED (logistics backlog rate, 1,0.35) \\
\hline Logistics industry capital growth & DELAY FIXED (logistics fixed assets, 3,36.5) \\
\hline
\end{tabular}

This paper argues that the regional GDP growth coefficient and proportion of fixed asset investment is changing over time, which can be given by Time's table function; while the proportion of logistics industry investment is decided by the logistics backlog impact factor's table function. The following is calculated by Changzhou City's Statistical Yearbook:

Regional GDP growth coefficient $=$ WITH LOOKUP (TIME, $([(2002,0)-(2020,0.5)],(2002,0.13),(2003,0.18)$, $(2004,0.22), \quad(2005,0.18), \quad(2006,0.20), \quad(2007,0.19)$, $(2008,0.17), \quad(2009,0.14), \quad(2010,0.18), \quad(2015,0.18)$, $(2020,0.15))$.

Proportion of Fixed assets investment $=$ WITH LOOKUP (TIME, ([(2002,0) - (2020,1)], (2002,0.32), (2003,0.495), $(2004,0.535), \quad(2005,0.591), \quad(2006,0.606), \quad(2007,0.640)$, $(2008,0.657), \quad(2009,0.676), \quad(2010,0.706), \quad(2015,0.50)$, $(2020,0.45))$.

Proportion of Logistics industry $=$ WITH LOOKUP (Logistics backlog factor, $([(0,0) \quad-\quad(20,0.1)]$,
$(0,0.00205),(1,0.00216), \quad(3,0.0250), \quad(5,0.0216)$, $(7,0.0204)))$.

\section{2 validity test}

In order to investigate the stability of Changzhou City's regional logistics industry development system, we select "Regional GDP"'s simulation value to test the stability of the model. We use time step of 1 year, 0.5 year and 0.25 year respectively to simulate the model and the result is shown in Fig. 2. The figure reflects the steady trend curve, indicating the model parameter is insensitive and the model is stable and reliable.

Table 2 shows the error and contrast between Changzhou City 's actual GDP level and predicted GDP level from 2002 to 2010 . We can see from the table that the amount of error is controlled within $10 \%$ and the fitting is good, indicating that the simulation Model's prediction of the future value is in line with the actual situation and the model reaches a high precision. 
TABLE II. STATE VARIABLES SIMULATION EFFECT TEST

\begin{tabular}{cccc}
\hline & $\begin{array}{c}\text { Changzhou City's total social product (GDP) (Unit: 100 million) } \\
\text { Year }\end{array}$ & predicted value & relative error \\
\hline 2002 & 760.60 & 760.60 & $0.00 \%$ \\
2003 & 901.42 & 856.20 & $-5.01 \%$ \\
2004 & 1101.35 & 1068.93 & $-2.94 \%$ \\
2005 & 1302.21 & 1331.3 & $2.23 \%$ \\
2006 & 1569.46 & 1474.55 & $-6.04 \%$ \\
2007 & 1880.00 & 1781.05 & $-5.26 \%$ \\
2008 & 2202.23 & 2168.62 & $-1.54 \%$ \\
2009 & 2518.7 & 2536.46 & $0.71 \%$ \\
2010 & 2976.7 & 2923.04 & $-1.80 \%$ \\
\hline
\end{tabular}

\section{B. Model Simulation}

The model simulation's period is from 2002 to 2020 and the step size of simulation is 1 year.

- simulation of the regional GDP. The result of regional GDP's simulation is shown in Figure 3. From the figure we can see from 2002 to 2020, Changzhou City's regional GDP has been rising steadily. In 2002 the GDP was 76.06 billion yuan, and in 2010 the GDP was 292.304 billion yuan. Despite the regional economic growth coefficient has fluctuated during this period, the regional GDP's development trend is not influenced by it.

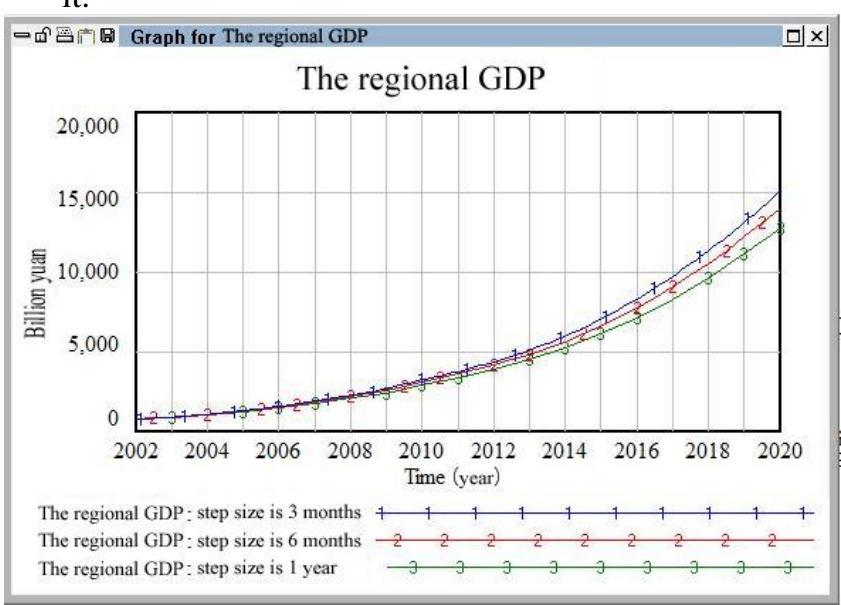

Figure 2. The stability test of the model

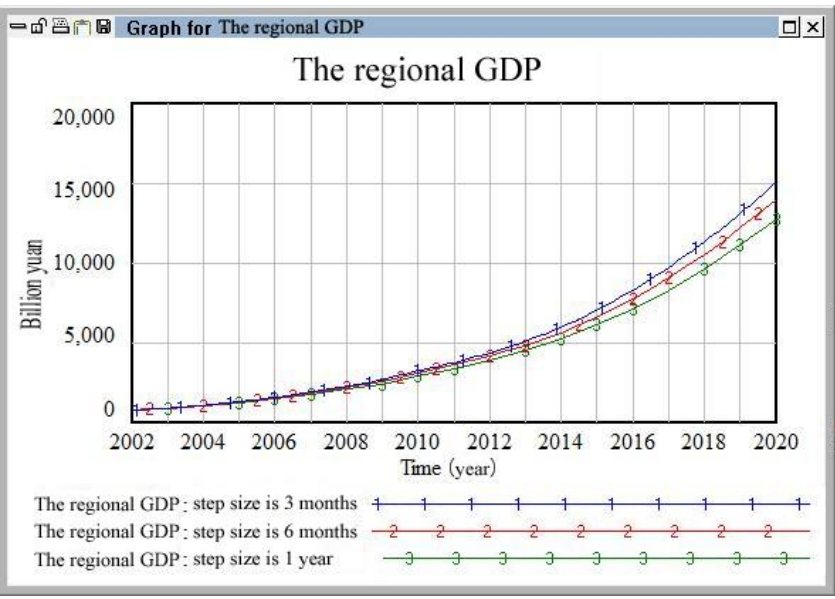

Figure 3. The results of regional GDP simulation

- Logistics backlog simulation. Logistics backlog simulation curve shown in Figure 4 shows that, due to the lack of regional logistics supply capacity, the needs of regional logistics can't be met, leading to the increase of logistics backlog year by year. After 2016, the rising range of logistics backlog will increase. 


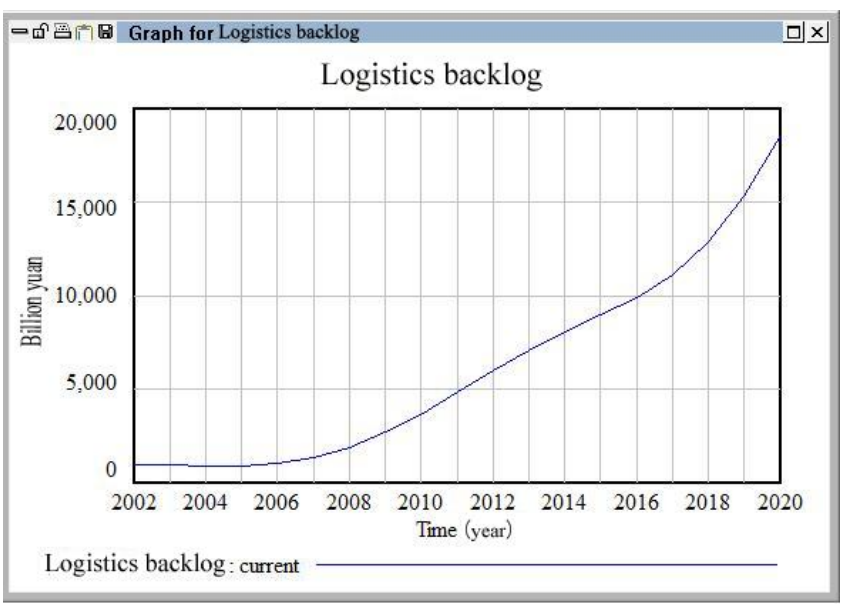

Figure 4. Simulation of logistics backlog

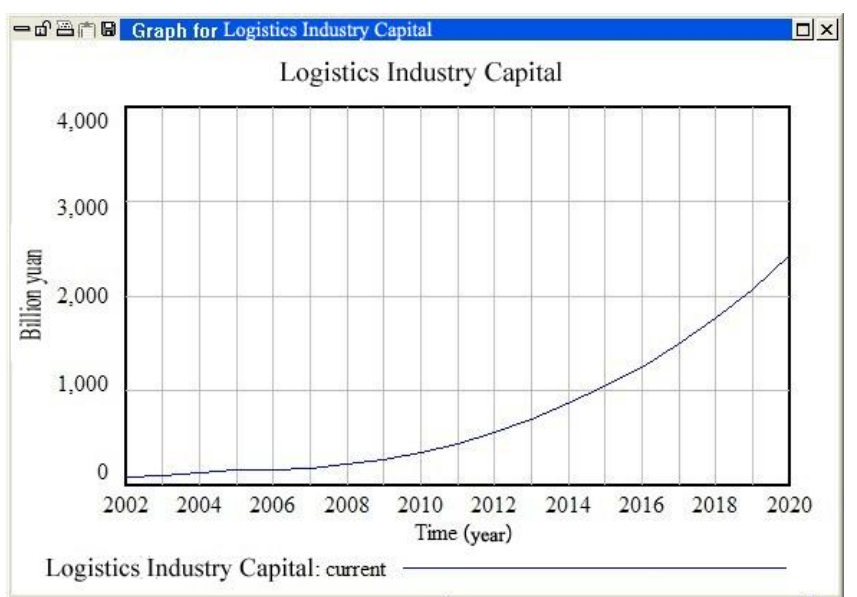

- Simulation of logistics industry capital. The result of Simulation of logistics industry capital is shown in Figure 5. We can see Changzhou City's logistics industry capital is in a steady growth, and during the period from 2002 to 2008 the growth momentum is slow. However, with the relevant government and enterprise's gradual emphasis on logistics industry development and increased investment in logistics fixed assets, beginning in 2009, the logistics industry capital has an increasing trend over time.

\section{2.4 Policy Simulation Analysis}

In practice, policy has an important influence on regional logistics industry, which is embodied in the following three aspects: First is fixed asset investment in logistics. The relevant government departments or enterprises can control regional logistics industry by adjusting the proportion of the logistics industry investment; second is logistics efficiency impact factor. By increasing investment in logistics education, the policy can encourage logistics enterprises to adopt advanced technology and equipment to improve the efficiency of logistics operations, thereby improving regional logistics supply capacity; the third is the capital conversion rate. Through continuous integration of existing resources and giving full play to the utilization efficiency of existing logistics industry capital, the policy can promote the rapid development of regional logistics industry.

In order to compare the pros and cons of various types of policies and seek to optimize the program of the system, this paper presents four strategic programs (shown as TABLE III) to compare the system dynamic changes of logistics industry under different strategic options.

Figure 5. Simulation of logistics industry capital

TABLE III. Table of alternatives comparison

\begin{tabular}{|l|l|l|}
\hline NO. & \multicolumn{1}{|c|}{ Name of program } & \multicolumn{1}{c|}{ Parameter adjustment } \\
\hline Option one & $\begin{array}{l}\text { Adjustment of logistics } \\
\text { industry } \\
\text { proportion }\end{array}$ & $\begin{array}{l}\text { Logistics industry investment proportion= WITH LOOKUP (Logistics backlog Rate promoter, } \\
([(0,0)-(20,0.1)],(0,0.00285),(1,0.00300),(3,0.035),(5,0.0450),(7,0.0500)))\end{array}$ \\
\hline Option II & $\begin{array}{l}\text { Adjustment of logistics } \\
\text { efficiency impact factor }\end{array}$ & $\begin{array}{l}\text { With other variable parameters remaining unchanged, we adjust the logistics efficiency impact } \\
\text { factor from0.35 to 0.45 so as to simulate the situation that by encouraging enterprises to adopt } \\
\text { advanced technology and equipment, and increase investment in education and other ways, the } \\
\text { logistics industry operational efficiency can be increased and regional Logistics status quo can be } \\
\text { improved. }\end{array}$ \\
\hline Option Three & $\begin{array}{l}\text { Adjustment of capital } \\
\text { conversion rate }\end{array}$ & $\begin{array}{l}\text { With other variable parameters remaining unchanged, we adjust the capital conversion rate from } \\
0.35 \text { to } 0.45 \text { so as to simulate the situation that external policy pays more attention to integrating } \\
\text { existing logistics resources and therefore improving utilization rate of logistics industry. }\end{array}$ \\
\hline Option IV & Hybrid strategy & $\begin{array}{l}\text { Adjustment of proportion of investment on the logistics industry, adjustment of logistics } \\
\text { efficiency impact factor, and adjustment of capital conversion rate. Logistics industry investment } \\
\text { proportion= WITH LOOKUP (Logistics backlog rate impact factor, ([(0,0) - }(20,0.1)], \\
(0,0.00205),(1,0.00320),(3,0.045),(5,0.0350),(7,0.0600)) ; \text { logistics efficiency impact factor }= \\
0.40 ; \text { capital conversion rate = 25. }\end{array}$ \\
\hline
\end{tabular}

Due to space limitations, we select regional GDP, logistics backlog and logistics backlog rate to make simulation analysis of policy and the result of simulation and emulation is shown in Fig. 6-8. 


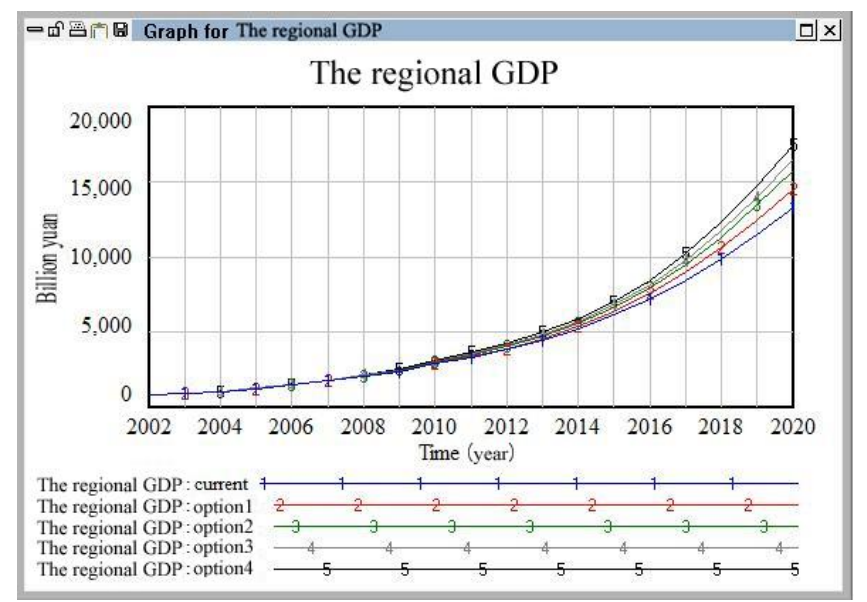

Figure 6. Fig.6 Four alternatives comparison of regional GDP

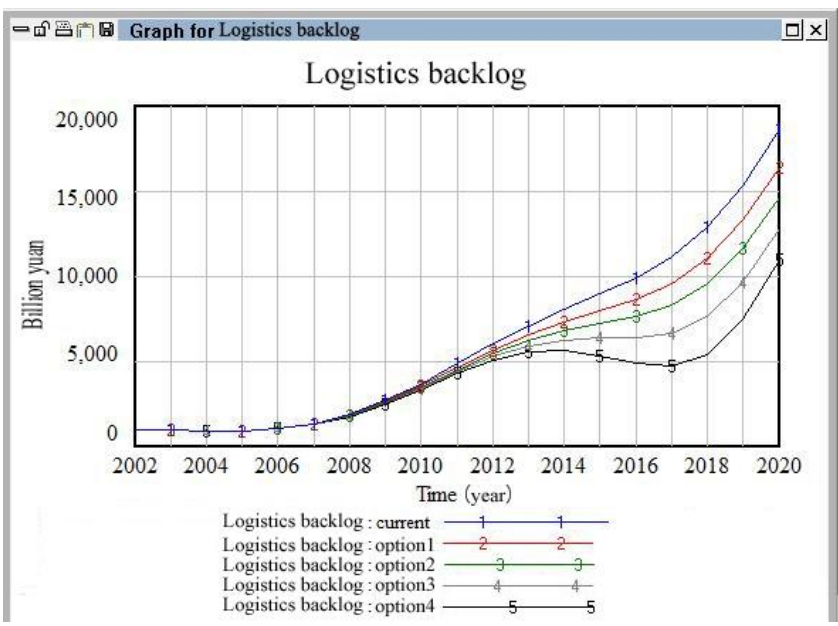

Figure 7. Four alternatives of logistics backlog

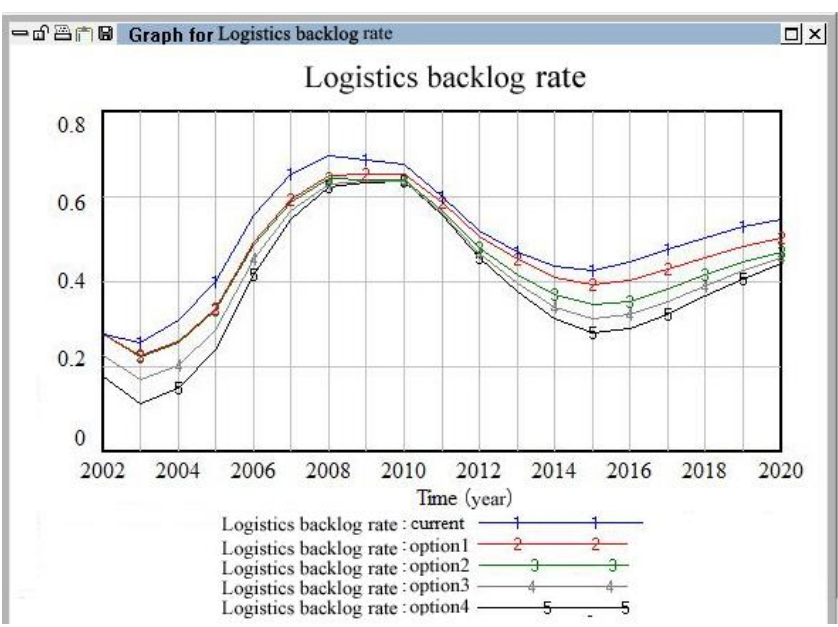

Figure 8. Four alternatives of logistics backlog rate

According to the analysis, the simulation result of four parameter-adjusted programs are all better than the basic simulation result. Regional GDP has increased and logistics backlog and logistics backlog rate have declined, indicating that these policies have played a positive role in promoting the development of the logistics industry and economy in Changzhou city. In addition, by observing historical simulation curves and policy simulation curve, we can see: (1) In order to promote the development of the logistics industry in Changzhou City, we shouldn't simply increase investment in logistics industry but should improve logistics operation efficiency and capital conversion rate. (2) Changzhou City's level of development of logistics industry is in its infancy, and relying solely on fixed asset investment to promote regional economic development is not sustainable. Coordinated developments of the logistics fixed asset investment, logistics operation efficiency and capital conversion rate are most favorable for Changzhou City's logistics development.

\section{CONCLUSION}

Regional Logistics Planning has an important value in the development of regional logistics industry. The paper has been studied regional logistics industry development strategy based on system dynamics, and through the simulation of Changzhou City's logistics industry development strategy, we find that this method has good application value. However, since the Changzhou City's regional logistics industry development system is a complexly and dynamically social and economic system, the statistics is a huge workload and part of the logistics data is difficult to obtain. Some of the parameters used are replaced by national data or other relevant data, to a certain extent, the accuracy of the model prediction may be reduced. Therefore, the follow-up study needs further optimization in data acquisition and other aspects, and appropriate increase in functional modules of the model is necessary. In addition, the regional logistics industry development system is a socio-economic system in which too much uncertainty, randomness, arbitrariness and uncontrollable factors, therefore, in order to better deal with complex social and economic problems, we can consider to integrate the input-output method, multi-objective linear programming model, AHP method and system dynamics model so as to benefit the study of regional logistics industry.

\section{ACKNOWLEDGEMENT}

This research was financially supported by the Ministry of Education Humanities and Social Science Planning Project (15YJA630103) and Open Foundation of Hubei Industry Policy and Management Research Center (cy20150102).

\section{REFERENCES}

[1] Hou Rui, Zhang Bixi, "Regional Logistics Demand Forecasting Method Based on MLP Neural Network and Its Application", Systems engineering theory and practice, pp.43-47, December 2005.

[2] Liu Nan, Li Yan, "Study on the Relationship between the Modern Logistics and Economic Growth", Journal of management engineering, pp.151-153, January. 2007.

[3] $\mathrm{Xu} \mathrm{Xi,} \mathrm{Huang} \mathrm{Zuqing,} \mathrm{"Study} \mathrm{on} \mathrm{the} \mathrm{Relationship} \mathrm{between} \mathrm{the}$ Regional Logistics and Regional Economic Development Interactive - 
Take Zhejiang Province as an Example", Statistics and decision, pp. 116-119, September. 2011.

[4] Wang Li, Han Zengling, Li Yajun, "Theory of Modern Regional Logistics Planning Framework”, Economic geography, pp. 601-605, September 2009.

[5] Shu Hui, Zhou Xideng, "Regional Logistics Industry Overall Development Pattern", China's circulation economy, pp. 22-25, September 2010.
[6] Sun Shusheng, Hai Feng, "The Regional Logistics System and the Operation Mode Based on Industrial Cluster", Logistics technology, pp.20-23, July 2006.

[7] Chen Liangchao, Lin Hua, "The forming mechanism and the SD model of the modern logistics industry", Journal of Shandong institute of transportation, pp. 42-44, February, 2008. 